\title{
Inhaled treprostinil: a therapeutic review
}

This article was published in the following Dove Press journal:

Drug Design, Development and Therapy

23 January 2012

Number of times this article has been viewed

\section{Richard N Channick' \\ Robert Voswinckel 2,3 \\ Lewis J Rubin ${ }^{4}$}

'Pulmonary Hypertension Program, Massachusetts General Hospital, Boston, MA, USA; ${ }^{2}$ University of Giessen Lung Center, Dept. of Internal Medicine, Giessen; ${ }^{3}$ Max-PlanckInstitute for Heart and Lung Research, Dept. of Lung Development and Remodeling, Bad Nauheim, Germany; ${ }^{4}$ University of California, San Diego, La Jolla, CA, USA
Correspondence: Richard N Channick Pulmonary Hypertension Program, Massachusetts General Hospital, Boston, MA, USA

Tel + I 6177243705

Fax + I 6177246954

Email rchannick@partners.org
Abstract: Pulmonary arterial hypertension (PAH) is a life-threatening disease which, if untreated, leads to right ventricular failure and often death. Several effective therapies are now available for $\mathrm{PAH}$, including endothelin receptor antagonists, phosphodiesterase-5 inhibitors, and prostacyclin analogs. The prostacyclin analog treprostinil has proven efficacious when delivered by subcutaneous or intravenous infusion, and most recently by inhalation. Inhaled treprostinil has been shown to be $64 \%-72 \%$ bioavailable in healthy volunteers. Pilot clinical studies have elucidated the acute hemodynamic effects and relative pulmonary selectivity of this agent, as well as established target dosing in PAH and nonoperable chronic thromboembolic PAH. Likewise, chronically administered inhaled treprostinil resulted in clinical and hemodynamic improvement. Both pilot studies confirmed a satisfactory safety profile in patients with PAH. The pivotal Phase III trial, TRIUMPH-I, demonstrated the efficacy and safety of inhaled treprostinil (target dose of $54 \mu \mathrm{g}$ four times daily) in PAH patients added to background therapies of bosentan or sildenafil, as assessed by improvements in the primary endpoint, peak six-minute walk distance (median placebo-corrected treatment effect of $20 \mathrm{~m}$ ), as well as select secondary endpoints. Inhaled treprostinil is approved by the US Food and Drug Administration for patients with World Health Organization Group I PAH to improve exercise ability. Studies establishing effectiveness included predominately patients with New York Heart Association functional class III symptoms and etiologies of idiopathic or heritable PAH (56\%) or PAH associated with connective tissue diseases (33\%).

Keywords: pulmonary arterial hypertension, prostacyclin, treprostinil, inhaled, nebulizer

\section{Introduction}

Pulmonary arterial hypertension (PAH) is a life-threatening disorder characterized by a widespread pulmonary vasculopathy, leading to elevation in pulmonary arterial pressure (PAP) and resultant right ventricular enlargement and dysfunction. Without therapy, death from progressive right ventricular failure is common. ${ }^{1}$ During the last 20 years, the development of PAH-specific therapies has led to both short- and long-term benefits to many patients. These "targeted" treatments were discovered by disrupting the normal balance of important mediators of pulmonary vasomotor tone and growth, including endothelin-1, nitric oxide, and prostacyclin. This "bench-to-bedside" translation has led to the approval of three classes of PAH therapies: endothelin receptor antagonists (ERAs), phosphodiesterase type 5 inhibitors (PDE-5Is), and prostacyclin analogs (Table 1).

The clinical development of currently approved therapies for PAH has followed a traditional path. Preclinical testing to demonstrate drug safety and activity has been 
Table I FDA-approved therapies for pulmonary arterial hypertension

Prostacyclin analogs

Epoprostenol: intravenous

lloprost: inhaled

Treprostinil: subcutaneous, intravenous, inhaled

Endothelin receptor antagonists

Bosentan: oral

Ambrisentan: oral

Phosphodiesterase-5 inhibitors

Sildenafil: oral, intravenous

Tadalafil: oral

followed by Phase I and II studies which typically include dose finding and preliminary indication of efficacy. Positive results in Phase II, have traditionally led to larger scale Phase III randomized, controlled trials with most often a primary endpoint of improvement in exercise capacity. ${ }^{2-9}$ In fact, most all of the currently approved PAH therapies have received their initial regulatory approval as monotherapy for the primary indication by improving six-minute walk distance (6MWD). Additional endpoints such as functional class, hemodynamics, and clinical worsening of PAH have also been included in most of these Phase III trials.

Given the availability of several therapies and routes of administration, the selection and timing of appropriate treatment(s) have become more complex. Various consensus guidelines have been developed to guide these decisions. ${ }^{10-12}$ Of the three classes of PAH therapies, parenteral prostacyclin analogs have been the most widely studied. Intravenous epoprostenol was the first US Food and Drug Administration (FDA)-approved treatment for PAH based on significant improvement of exercise capacity and significant reduction of mortality after 12 weeks. ${ }^{2}$ However, due to its extremely short in vitro half-life (less than $6 \mathrm{~min}$ in human blood at $37^{\circ} \mathrm{C}$ and $\mathrm{pH} 7.4$ ), epoprostenol must be delivered as a continuous intravenous infusion through an indwelling catheter, with the risk of rebound $\mathrm{PAH}$ and acute right heart failure in case of infusion interruption. Furthermore, due to the inherent chemical instability of one form of epoprostenol (FLOLAN $^{\circledR}$; GlaxoSmithKline, Research Triangle Park, $\mathrm{NC}$ ) at room temperature and neutral $\mathrm{pH}$, ice packs may be needed to slow decomposition throughout the infusion period. A thermostable epoprostenol preparation for infusion (VELETRI ${ }^{\circledR}$; Actelion Pharmaceuticals US, Inc, San Francisco, CA), which does not require cooling, has recently been approved for use by the FDA.

To address these potential limitations of epoprostenol, longer-acting prostacyclin analogs have been developed, including iloprost and treprostinil. These agents have, with regional global differences, been approved for intravenous infusion (iloprost is not approved in the US for intravenous route) and, in the case of treprostinil, subcutaneous infusion. The pharmacological and physiochemical properties of iloprost and treprostinil also make both agents amenable to intermittent administration via the inhaled route using ultrasonic nebulizers specific to each therapy. Data have emerged confirming the benefit of using inhaled prostacyclin analogs for PAH therapy. ${ }^{4,13}$

This review focuses on the clinical development of inhaled treprostinil. Pharmacological aspects of this agent and currently available preclinical pharmacology and clinical data will be discussed. A perspective on the role of inhaled treprostinil for PAH is also discussed.

\section{Preclinical pharmacology and pharmacokinetics}

Treprostinil is a chemically stable tricyclic benzindene prostanoid with a molecular weight of 390.52 and a molecular formula of $\mathrm{C}_{23} \mathrm{H}_{34} \mathrm{NaO}_{5}$ (Figure 1). Inhaled treprostinil was first tested in a sheep model of pulmonary hypertension: Following a $\mathrm{PGH}_{2}$ analog, which caused marked pulmonary vasoconstriction, inhaled treprostinil completely normalized pulmonary vascular resistance (PVR) with minimal systemic blood pressure effects. ${ }^{14}$

Unlike epoprostenol which has an in vitro half-life of less than 6 min in human blood, treprostinil has an in vivo terminal elimination half-life of 4.6 hours following continuous subcutaneous infusion in normal volunteers. ${ }^{15}$ In vitro, $91 \%$ of treprostinil is bound to human plasma proteins. No

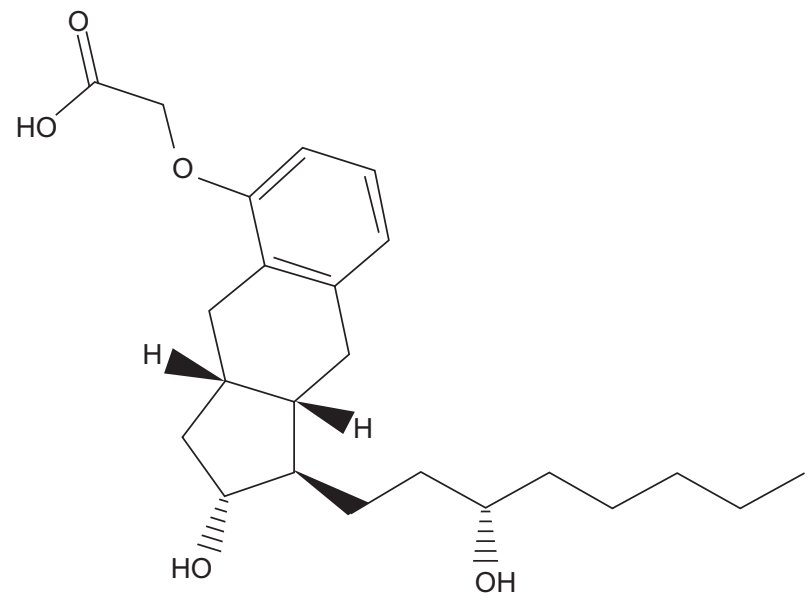

Figure I Structural formula of treprostinil. Treprostinil is (IR,2R,3aS,9aS)[[2,3,3a,4,9,9a-hexahydro-2-hydroxy-I-[(3S)-3-hydroxyoctyl]- I Hbenz[f]inden-5yl] oxy]acetic acid. Treprostinil has a molecular weight of 390.52 and a molecular formula of $\mathrm{C}_{23} \mathrm{H}_{34} \mathrm{O}_{5}$. 
effect on digoxin or warfarin displacement was detected. Treprostinil undergoes extensive oxidative metabolism in the liver, primarily by CYP2C8 and to a lesser extent CYP2C9. When subcutaneously administered, only $4 \%$ of treprostinil is excreted unchanged in urine. Although several urinary metabolites have been identified, none possess significant pharmacologic activity. No significant pharmacokinetic interactions have been found with treprostinil ethanolamine when administered orally with bosentan or sildenafil, which are commonly used agents in treating PAH. ${ }^{16}$

In two pilot studies with PAH patients, detectable levels of treprostinil were found in the systemic circulation following inhalation. ${ }^{17,18}$ The bioavailability of inhaled treprostinil was evaluated in 18 healthy volunteers using a three-period crossover study design comparing two doses of inhaled treprostinil (18 and $36 \mu \mathrm{g}$ ) and intravenous treprostinil. ${ }^{19}$ The two doses achieved $64 \%$ and $72 \%$ bioavailability, respectively. The mean maximum plasma concentration $\left(\mathrm{C}_{\max }\right)$ for the $18 \mu \mathrm{g}$ and $36 \mu \mathrm{g}$ doses were 354 and $698 \mathrm{pg} / \mathrm{mL}$, respectively, with a time to maximum plasma concentration $\left(\mathrm{T}_{\max }\right)$ of 0.15 hours. Treprostinil remained detectable in the plasma for up to 3.5 hours after inhalation.

A Phase I single dose escalation study in healthy volunteers $(n=40)$ showed that the maximum tolerated dose of inhaled treprostinil sodium was $84 \mu \mathrm{g}$ (14 breaths). ${ }^{19}$ The pharmacokinetic parameters, $\mathrm{C}_{\max }$ (Figure 2) and area under the curve (AUC) generally increased with increasing dose between 54 to $90 \mu \mathrm{g}$. The mean $\mathrm{C}_{\max }$ at the FDA recommended human dosage of $54 \mu \mathrm{g}$ (nine breaths) dose was $0.91 \mathrm{ng} / \mathrm{mL}$ with a corresponding mean $\mathrm{T}_{\text {max }}$ of 0.21 hours. The mean AUC for the $54 \mu \mathrm{g}$ dose was $0.81 \mathrm{ng}-\mathrm{hr} / \mathrm{mL}$, respectively. Studies of treprostinil administered by subcutaneous or intravenous infusion have shown that the elimination of treprostinil is biphasic, with a terminal elimination half-life of 4.4 and 4.6 hours, respectively. ${ }^{15}$ Given the relatively low systemic plasma concentrations achieved following treprostinil inhalation, a multicompartment model cannot be applied and, therefore, the terminal elimination half-life cannot be estimated. Analysis of the data obtained from a Phase I single dose escalation study $(n=40)$ of inhaled treprostinil using a noncompartmental model provided an estimate of the apparent half-life for treprostinil that ranged from 0.54 to 0.76 hours (Figure 2).

\section{Clinical uses}

Treprostinil was initially studied as a continuous subcutaneous infusion. In a pivotal 12 week randomized, controlled trial of 470 patients, subcutaneous treprostinil significantly improved exercise capacity compared with placebo. ${ }^{3}$ The between treatment group difference in median 6MWD was 16 meters $(P=0.006)$. Importantly, the effect on exercise capacity appeared to be dose-dependent. A long-term follow-up study

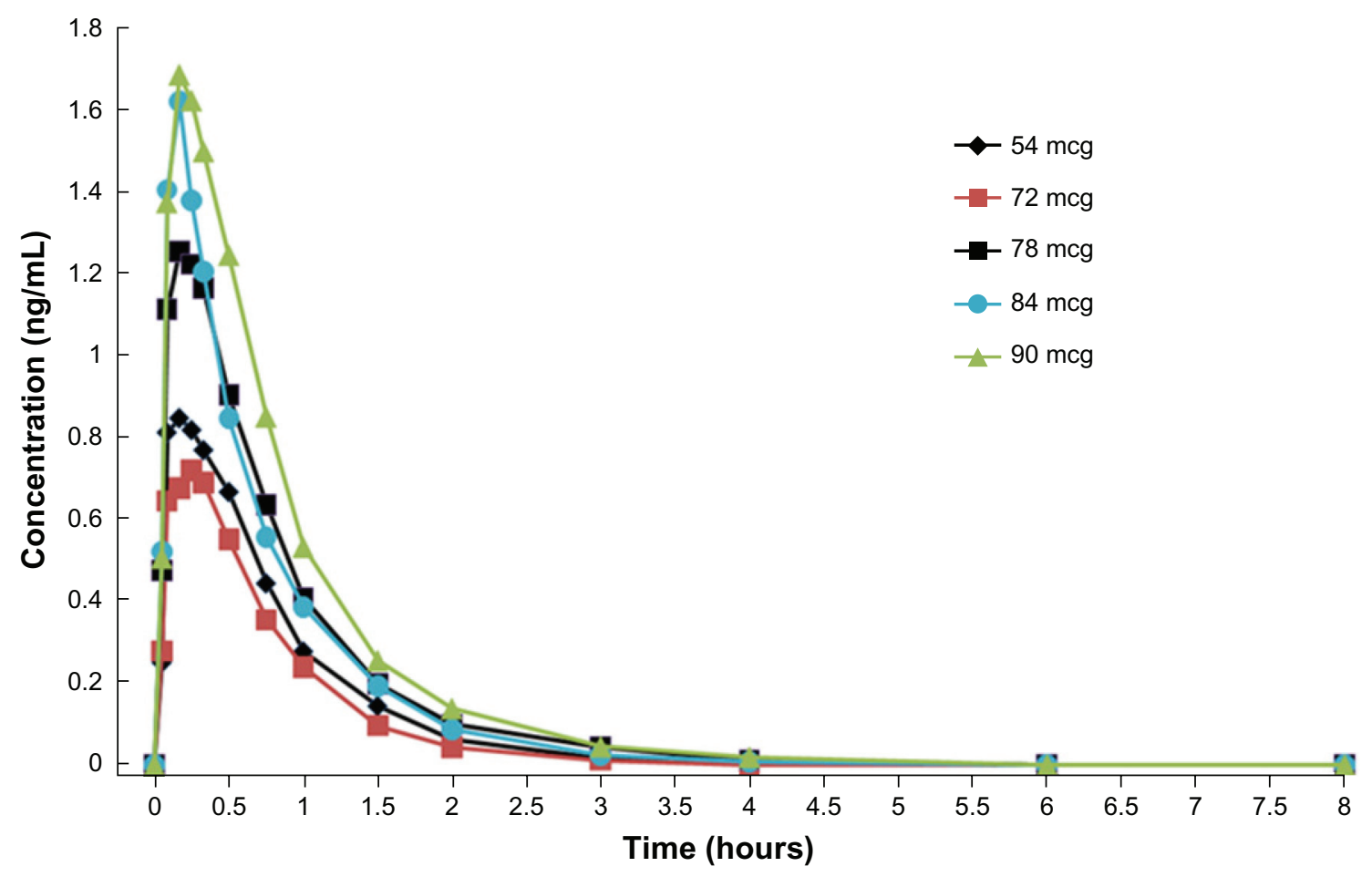

Figure 2 Plasma concentrations following inhalation of various doses of treprostinil. 
of 806 patients reported by Barst and colleagues ${ }^{20}$ confirmed the durability of effect of subcutaneous treprostinil, with favorable survival compared to historical controls. One particular adverse effect, infusion site pain, led to discontinuation of drug in $8 \%$ of subcutaneous treprostinil-treated patients. Mathier and colleagues ${ }^{21}$ have summarized numerous practical considerations related to achieving symptomatic pain relief while using subcutaneous treprostinil. Although most often manageable, the frequency of infusion site pain led ultimately to the development and FDA approval of treprostinil as a continuous IV infusion. The efficacy of IV treprostinil was demonstrated in a 16-week open-label trial of 16 patients ${ }^{22}$ followed by a 44 patient randomized placebo-controlled trial that demonstrated improvement in 6MWD. ${ }^{23}$

\section{Clinical data of inhaled treprostinil}

Treprostinil delivered intermittently to the pulmonary circulation, ie, four times daily via inhalation using an OptiNeb ultrasonic nebulizer (NebuTec, Elsenfeld, Germany) (Figure 3) appears to be an effective treatment for PAH. Given treprostinil's longer half-life and its relative selectiv-

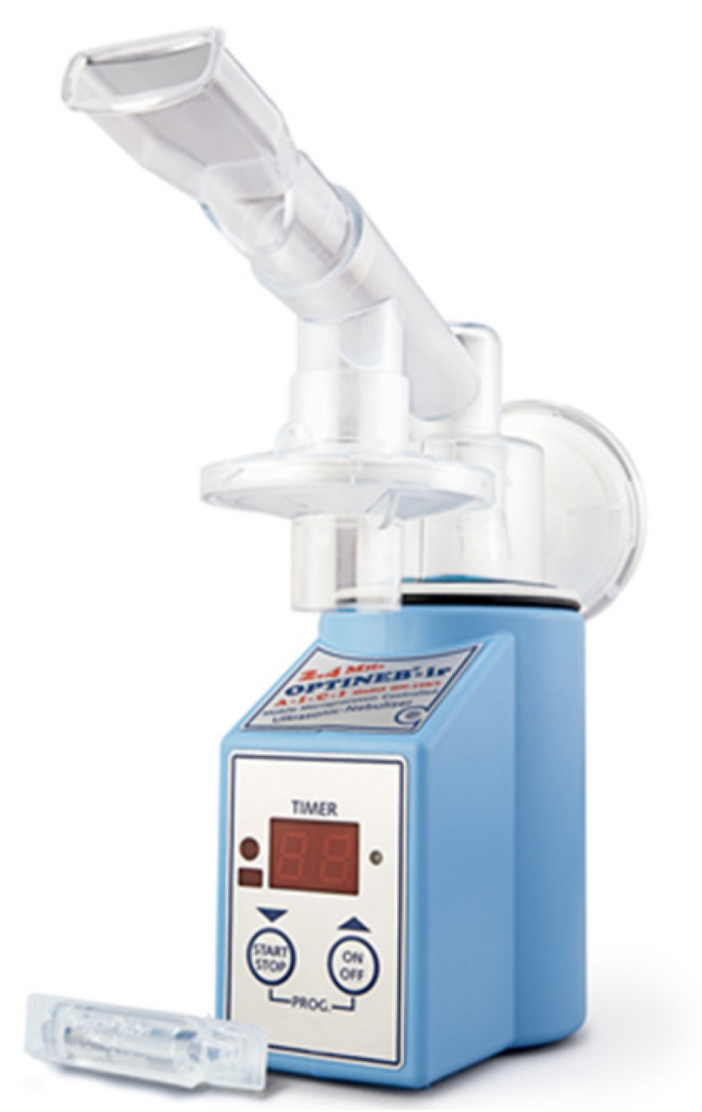

Figure 3 Tyvaso Inhalation System. Tyvaso is intended for oral inhalation using the Tyvaso Inhalation System, which consists of the Opti-Neb-ir Model ON-100/7 (NebuTec, Elsenfeld, Germany), an ultrasonic, pulsed-delivery device. ity for the pulmonary circulation as compared to iloprost, ${ }^{17}$ there was a strong rationale for developing treprostinil for inhalation. The ability of modern ultrasonic nebulizers to decrease and control particle size make these devices ideal for delivering prostacyclin analogs to the distal airspaces, which are in close proximity to the resistance pulmonary arterioles.

The first published human study of inhaled treprostinil was a hemodynamic study in three treatment-naïve patients with severe $\mathrm{PAH} .{ }^{24} \mathrm{~A}$ single dose of $15 \mu \mathrm{g}$ resulted in a reduction in PVR of approximately $45 \%$. One of these patients had an excellent vasodilator response and was further treated with high-dose calcium channel blockers. Two of these patients continued therapy with reported improvements in exercise capacity and functional class.

A follow-up pilot study, comprising acute hemodynamic and pharmacokinetic investigations, was conducted by Voswinckel and colleagues ${ }^{17}$ and compared the effects of inhaled treprostinil and inhaled iloprost in a crossover design (Figure 4). It was found that both agents resulted in comparable maximal decreases in PVR. However, the peak effect of inhaled treprostinil occurred later than with inhaled iloprost (18 \pm 2 vs $8 \pm 1 \mathrm{~min})$. The duration of the treprostinil effect (after 60 minutes postinhalation, PVR was not back to baseline) was longer as compared to the iloprost effect (after 60 minutes postinhalation, PVR had returned to baseline). In addition, these investigators found that: (1) the maximal acute hemodynamic effect was seen at a dose of $30 \mu \mathrm{g}$ of inhaled treprostinil with a duration of effect lasting as long as three hours; (2) this dose could be safely delivered in one inhalation; and (3) doses up to $60 \mu \mathrm{g}$ could be safely delivered in one single inhalation. These data confirmed the potent and sustained nature of inhaled treprostinil as a pulmonary vasodilator.

Voswinckel and colleagues ${ }^{25}$ also investigated the safety and acute hemodynamic effects of the combination of single doses of oral sildenafil $(50 \mathrm{mg})$ and inhaled treprostinil (15 or $30 \mu \mathrm{g}$ ) in an open-label study in patients with precapillary pulmonary hypertension. Compared to baseline, oral sildenafil reduced PVR to $80.1 \% \pm 5.0 \%$, mean PAP to $86.5 \% \pm 2.9 \%$ and increased CO to $103.8 \% \pm 3.2 \%$. Treprostinil, inhaled one hour after sildenafil, reduced PVR further to $66.3 \% \pm 3.8 \%$, mean PAP to $77.8 \% \pm 3.3 \%$, and increased CO to $107.1 \%$ $\pm 3.3 \%$ (mean $\pm 95 \%$ confidence interval). Subgroup analysis showed similar acute hemodynamic effects in PAH and chronic thromboembolic pulmonary hypertension (CTEPH) patients. Ventilation/perfusion distribution measurement in six patients with preexisting gas exchange limitations was not 
PVR

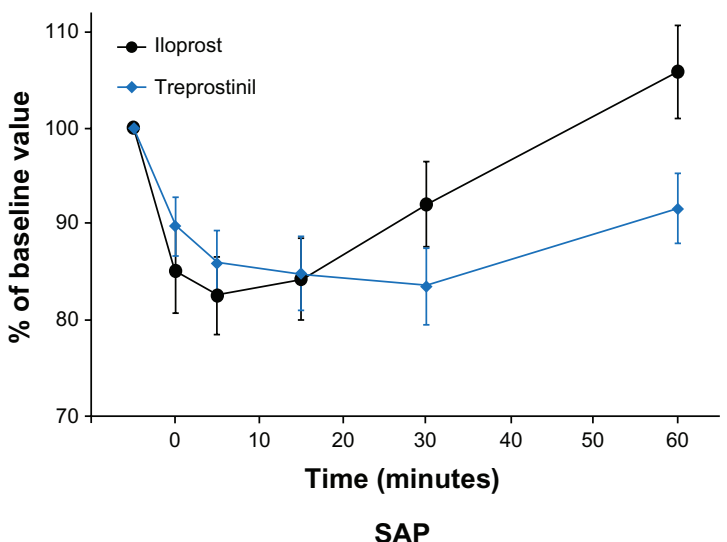

SAP

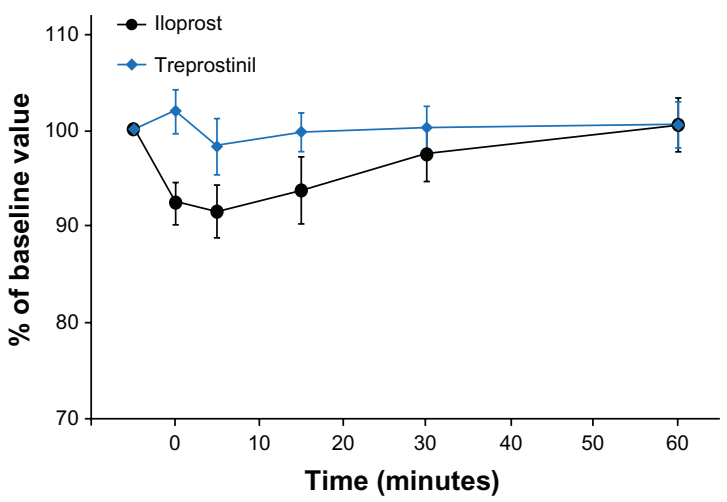

PAP
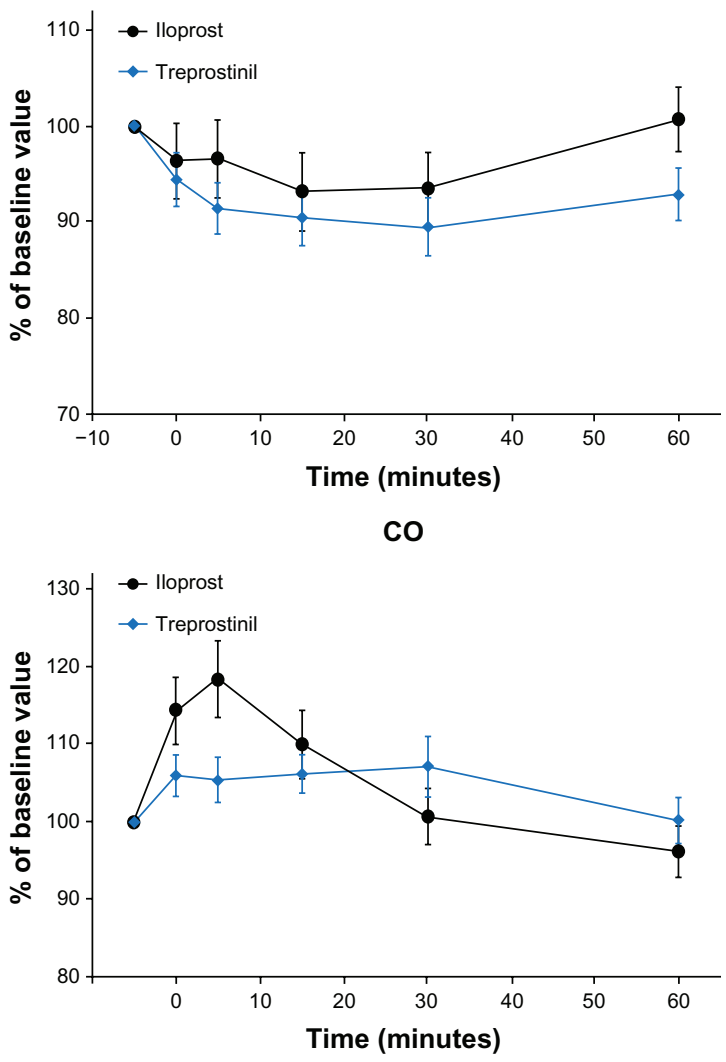

Figure 4 Comparison of acute hemodynamic effects of inhaled treprostinil and inhaled iloprost in patients with pulmonary arterial hypertension. ${ }^{17}$ Abbreviations: CO, cardiac output; PAP, pulmonary artery pressure; PVR, pulmonary vascular resistance; SAP, systemic artery pressure.

changed by sildenafil and treprostinil. Relevant side effects were not observed. Thus, the combination of sildenafil and inhaled treprostinil appeared to be well-tolerated and induced additive, pulmonary selective vasodilatation in pulmonary hypertension patients.

Given that hemodynamic effects following acute dosing do not always correlate with long term clinical benefits, additional long-term efficacy studies were conducted, including evaluation as an add-on therapy to oral PAH medications. Channick and colleagues conducted a pilot, 12-week open label trial evaluating the efficacy and safety of two doses of inhaled treprostinil in 12 patients with PAH concurrently receiving bosentan. ${ }^{18}$ Patients were treated with $30 \mu \mathrm{g}(\mathrm{n}=6)$ or $45 \mu \mathrm{g}(\mathrm{n}=6)$ four times daily. Hemodynamics, exercise capacity, functional class, pharmacokinetics, and safety were assessed. Acutely, inhaled treprostinil decreased mean PAP in a dose-dependent manner. Additionally, the study demonstrated that inhaled treprostinil given chronically was welltolerated with an acceptable safety profile with common side effects including transient cough $(\mathrm{n}=5)$, headache $(\mathrm{n}=4)$, and sore throat $(\mathrm{n}=2)$, but no serious adverse events. Hemodynamics were improved, with significant decreases noted in mean PAP (10\% decrease measured at peak postinhalation, approximately one hour) and a trend toward improvement in cardiac index (15\% increase) and PVR (26\% decrease). Significant improvements in both peak (67 meters) and trough (49 meters) 6MWDs were noted. Nine of 11 patients noted improvement in functional class from III to II.

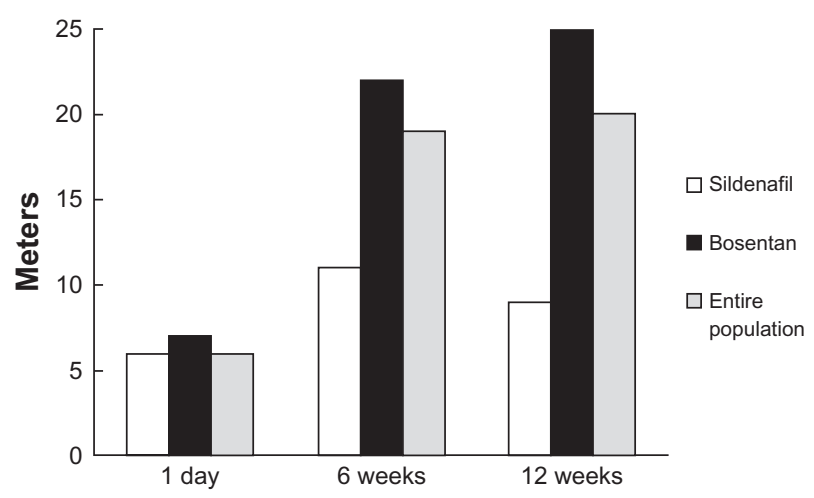

Figure 5 Change in six-minute walk distance (6MWD) with inhaled treprostinil in TRIUMPH-1. ${ }^{13}$ Primary end-point, change in peak 6MWD for patient receiving background sildenafil (white bars), background bosentan (black bars), and the entire population (solid bars). There was a placebo-corrected improvement of $20 \mathrm{~m}$ at 12 weeks in the total population. Results presented as Hodges-Lehman betweentreatment median difference. 
Given the positive results from these pilot studies, a randomized placebo-controlled trial was conducted (TRIUMPH-I; TReprostinil Sodium Inhalation Used in the Management of Pulmonary Arterial Hypertension). ${ }^{13}$ Two hundred thirty-five PAH patients, with persistent WHO functional class III and IV symptoms despite receiving oral bosentan or sildenafil for at least three months, were randomized to receive either inhaled treprostinil (nine inhalations, $54 \mu \mathrm{g}$ four times daily) or placebo, delivered via the Opti-Neb nebulizer. The primary endpoint was the 12-week placebo-corrected median change in peak (obtained 10 to 60 minutes postinhalation) 6MWD compared to baseline. Secondary endpoints included time to clinical worsening (death, transplantation, hospitalization due to worsening $\mathrm{PAH}$, or initiation of additional approved PAH-specific therapy), functional class, quality of life measures, trough 6MWD, and N-terminal pro-brain natriuretic peptide (NT-proBNP) levels.

Baseline characteristics of the patients in TRIUMPH-I are shown in Table 2, demonstrated that patients were still quite symptomatic with impairment in function and exercise capacity despite being on a stable dose of either bosentan (125 mg bid) or sildenafil ( $\geq 20 \mathrm{mg}$ tid) for at least three months. At the end of 12 weeks, there was a highly significant $(P=0.0004) 20 \mathrm{~m}$ placebo-corrected median improvement in 6MWD. Not surprisingly, there was a distribution of effect on 6MWD (Figure 6). Fifty-two percent of patients receiving treprostinil for 12 weeks had improvements of $20 \mathrm{~m}$ or more, while $31 \%$ of treprostinil-treated patients walked $50 \mathrm{~m}$ or more compared with baseline.

Table 2 Baseline characteristics of patients entering TRIUMPH ${ }^{13}$

\begin{tabular}{|c|c|c|c|}
\hline Characteristic & $\begin{array}{l}\text { Inhaled TRE } \\
(n=1 \mid 5)\end{array}$ & $\begin{array}{l}\text { Placebo } \\
(n=120)\end{array}$ & $P$ value \\
\hline Age, years & $55(20-75)$ & $52(18-75)$ & 0.056 \\
\hline Male/female & $22 / 93$ & $22 / 98$ & 0.88 \\
\hline \multicolumn{4}{|l|}{ PAH etiology } \\
\hline $\mathrm{PAH}$ or familial & $64(56)$ & $67(56)$ & 0.60 \\
\hline CVD & $40(35)$ & $37(31)$ & \\
\hline Other & II (9) & $16(13)$ & \\
\hline \multicolumn{4}{|l|}{ Background PAH therapy } \\
\hline Bosentan & $77(67)$ & $88(73)$ & 0.29 \\
\hline Sildenafil & $38(33)$ & $32(27)$ & \\
\hline \multicolumn{4}{|c|}{ Time on background therapy weeks } \\
\hline Bosentan & $99 \pm 79$ & $90 \pm 75$ & 0.62 \\
\hline Sildenafil & $65 \pm 60$ & $77 \pm 69$ & 0.44 \\
\hline Baseline NYHA III/IV & $112 / 3$ & $118 / 2$ & 0.62 \\
\hline Baseline 6MWD, meters & $346 \pm 63$ & $351 \pm 69$ & 0.50 \\
\hline
\end{tabular}

Notes: Values are mean (range), $\mathrm{n}, \mathrm{n}(\%)$, or mean \pm SD.

Abbreviations: 6MWD, six-minute walk distance; CVD, collagen vascular disease; NYHA, New York Heart Association; PAH, pulmonary arterial hypertension; $\mathrm{SD}$, standard deviation; TRE, treprostinil.
The secondary endpoints of time to clinical worsening, Borg dyspnea score, and New York Heart Association (NYHA) functional class were not significantly improved by inhaled treprostinil, most likely owing to the short duration of this 12 week study and that patients were on stable doses of bosentan or sildenafil monotherapy. Despite this, Minnesota Living with Heart Failure (MLWHF) questionnaire global and physical quality of life scores were improved $(P=0.027$ and 0.037 , respectively for median between-treatment difference), as were plasma NT-proBNP levels $(-187 \mathrm{pg} / \mathrm{mL}$ at week 12 , $P=0.0014$ ). Importantly, trough 6MWD (conducted prior to the next scheduled inhalation $>$ four hours) was significantly improved in the treprostinil group compared to placebo (median 14-m treatment effect, $P=0.0066$ ), suggesting a sustained effect of the medication.

Overall treatment with treprostinil for 12 weeks was fairly well-tolerated. The most commonly occurring adverse events are summarized in Table 3.

\section{Indications and usage}

Based on the results of the TRIUMPH-I study, on July 30, 2009 inhaled treprostinil received FDA approval under the trade name Tyvaso (United Therapeutics Corporation, Silver Spring, MD). As of February 8, 2011, Tyvaso is indicated for the treatment of PAH (WHO Group 1) to improve exercise ability. Studies establishing effectiveness included predominately patients with NYHA functional class III symptoms and etiologies of idiopathic or heritable $\mathrm{PAH}(56 \%)$ or $\mathrm{PAH}$ associated with connective tissue diseases (33\%). The effects diminish over the minimum recommended dosing interval of four hours; treatment timing can be adjusted for planned activities. While there are long-term data on use of treprostinil by other routes of administration, nearly all controlled clinical experience with inhaled treprostinil has been on a background of bosentan (an endothelin receptor antagonist) or sildenafil (a PDE-5I). The controlled clinical experience was limited to 12 weeks in duration.

\section{Dosage and administration} Usual dosage in adults

Tyvaso is intended for oral inhalation using the Tyvaso Inhalation System, which consists of the Opti-Neb-ir Model ON-100/7 (an ultrasonic, pulsed-delivery device) and its accessories. Tyvaso is dosed in four separate, equally spaced treatment sessions per day, during waking hours. The treatment sessions should be approximately four hours apart.

Initial therapy should begin with three breaths of Tyvaso (18 $\mu \mathrm{g}$ of treprostinil), per treatment session, four times daily. 


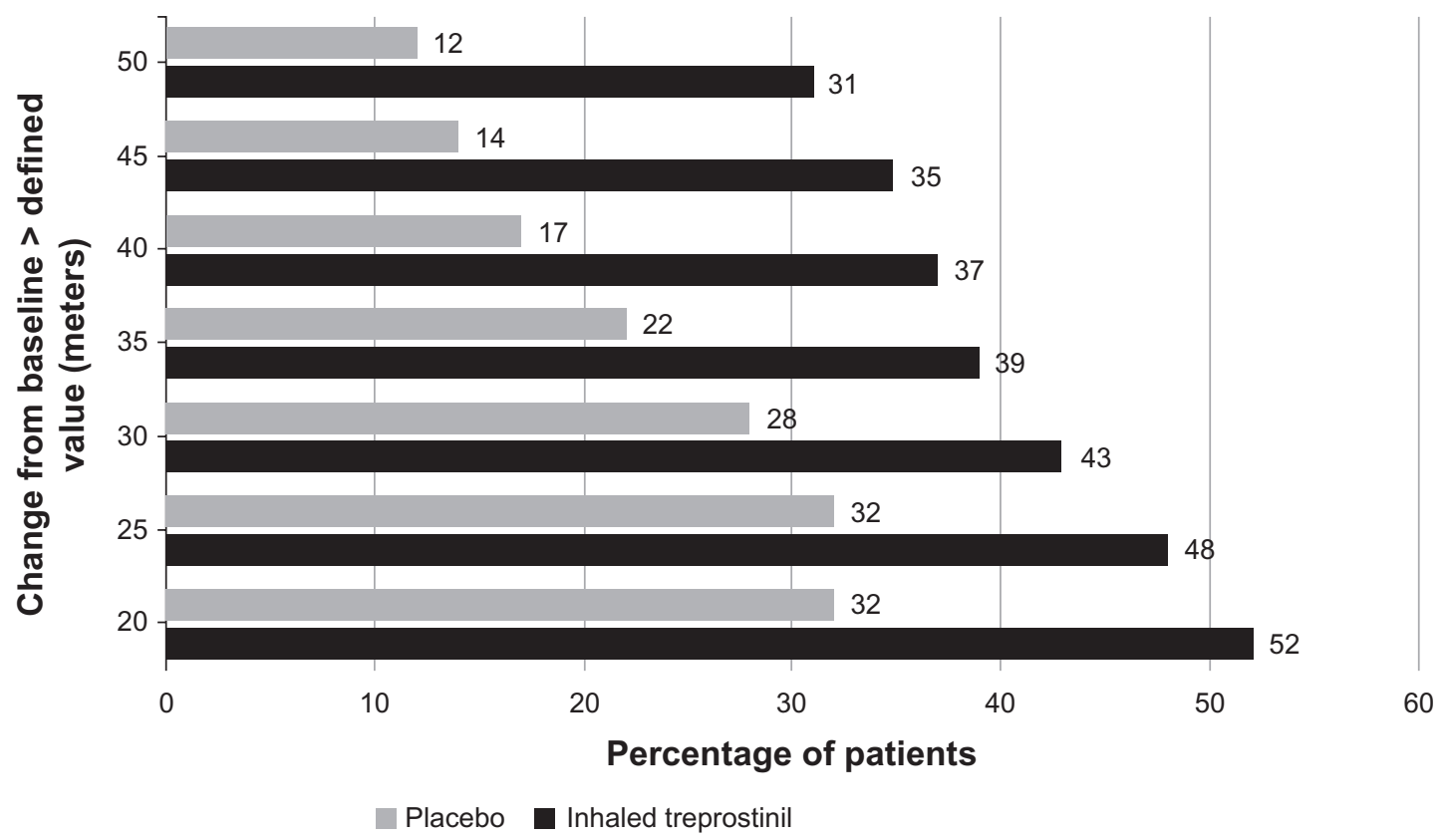

Figure 6 Distribution of six-minute walk distance (6MWD) improvements from inhaled treprostinil vs placebo groups in TRIUMPH-I. ${ }^{13}$ The graph illustrates the percentage of patients who achieved specific improvements in 6MWD at 12 weeks. For example, $31 \%$ of patients taking inhaled treprostinil and $12 \%$ of patients taking inhaled placebo had an improvement in 6MWD of $>50 \mathrm{~m}$ at 12 weeks.

If three breaths are not tolerated, reduce to one or two breaths and subsequently increase to three breaths, as tolerated. Dosage should be increased by an additional three breaths at approximately 1-2 week intervals, if tolerated, until the target dose of nine breaths ( $54 \mu \mathrm{g}$ of treprostinil) is reached per treatment session, four times daily. If adverse effects preclude titration to target dose, Tyvaso should be continued at the highest tolerated dose. If a scheduled treatment session is missed or interrupted, therapy should be resumed as soon as possible at the usual dose. The maximum recommended dosage is nine breaths per treatment session, four times daily.

\section{Warnings and precautions}

Safety and efficacy have not been established in patients with significant underlying lung disease (such as asthma or chronic

Table 3 Adverse events occurring in the TRIUMPH-I trial ${ }^{13}$

\begin{tabular}{|c|c|c|}
\hline \multirow{2}{*}{$\begin{array}{l}\text { Adverse events occurring in }>3 \% \\
\text { of treprostinil patients }\end{array}$} & \multicolumn{2}{|l|}{ Treatment } \\
\hline & $\begin{array}{l}\text { Inhaled TRE } \\
(n=1 \mid 5)\end{array}$ & $\begin{array}{l}\text { Placebo } \\
(n=120)\end{array}$ \\
\hline Cough & $62(54)$ & $35(29)^{*}$ \\
\hline Headache & $47(41)$ & $27(23)^{*}$ \\
\hline Nausea & 22 (19) & $13(11)$ \\
\hline Dizziness & $20(17)$ & $18(15)$ \\
\hline Flushing & $17(15)$ & $\mathrm{I}(<\mathrm{I})^{*}$ \\
\hline Throat irritation & $16(14)$ & $10(8)$ \\
\hline Pharyngolaryngeal pain & I3 (II) & $7(6)$ \\
\hline Diarrhea & II (I0) & $9(8)$ \\
\hline
\end{tabular}

Notes: Values shown are $\mathrm{n}(\%) . * p<0.05$. obstructive pulmonary disease). In patients with low systemic arterial pressure, Tyvaso may cause symptomatic hypotension. Tyvaso may increase the risk of bleeding, particularly in patients receiving anticoagulants. Tyvaso dosage adjustments may be necessary if inhibitors or inducers of CYP2C8 are added or withdrawn. Hepatic or renal insufficiency may increase exposure and decrease tolerability.

\section{Additional clinical data TRIUMPH-I open label extension}

Following completion of the 12-week double-blind phase of TRIUMPH-I, 206 of the original 235 patients transitioned into the long-term, open-label extension trial. Previously reported interim data from these patients ${ }^{26}$ showed that exercise capacity as assessed by $6 \mathrm{MWD}$ continued to improve: $31(\mathrm{n}=88), 34(\mathrm{n}=50)$, and $50 \mathrm{~m}(\mathrm{n}=17)$ at 12,18 , and 24 months, respectively. Improvements in MLWHF global, physical and emotional scores were also observed, while maintaining a similar adverse event profile.

\section{Transitioning from inhaled iloprost to inhaled treprostinil}

Given the availability of a longer-acting, effective inhaled prostacyclin analog, the potential of transitioning patients from the shorter acting iloprost to inhaled treprostinil was examined..$^{27}$ A 24-month, multicenter, prospective, open-label trial was designed to evaluate the long-term safety 
in PAH patients $(n=73)$ of transitioning from a stable dose of inhaled iloprost to inhaled treprostinil. Data from an interim analysis of 55 patients provided preliminary evidence supporting the safety of rapid transition from inhaled iloprost to inhaled treprostinil while maintaining exercise capacity and improving quality of life. Overall, patients noted significantly improved CAMPHOR (a PH-specific quality of life tool) scores after inhaled treprostinil treatment compared with baseline values on iloprost treatment. In addition, the total time spent per day administering inhaled treprostinil was reduced by $66 \%$ ( 81 minutes) compared with that for iloprost at baseline. Significant improvement in median 6MWD was observed after 12 weeks of inhaled treprostinil therapy (426 m vs $388 \mathrm{~m}$ at baseline on iloprost; $P=0.002$ ). Significant improvements in NT-proBNP were also observed at 6 and 12 weeks of treprostinil therapy (519 and $419 \mathrm{pg} / \mathrm{mL}$ vs $580 \mathrm{pg} / \mathrm{mL}$ at baseline on iloprost; $P<0.01$ for both).

\section{Treprostinil delivery via metered dose inhaler}

Based on data indicating that a therapeutic dose of treprostinil could be delivered in a single breath, ${ }^{17}$ Voswinckel and colleagues ${ }^{28}$ evaluated the acute hemodynamic effects of the drug delivered by a metered dose inhaler (MDI). A total of 39 patients (23 PAH, 16 nonoperable CTEPH) were randomized to receive placebo or one of the following doses: two puffs of $1,000 \mu \mathrm{g} / \mathrm{mL}(30 \mu \mathrm{g})$, three puffs of $1,000 \mu \mathrm{g} / \mathrm{mL}(45 \mu \mathrm{g})$ or two puffs of $2,000 \mu \mathrm{g} / \mathrm{mL}$ $(60 \mu \mathrm{g})$. Acute hemodynamic effects were compared to inhaled nitric oxide. Doses of 30, 45, and $60 \mu \mathrm{g}$ of inhaled treprostinil reduced PVR from $575 \pm 104$ dynes to $494 \pm 109$ dynes, from $964 \pm 184$ dynes to $720 \pm 229$ dynes, and from $667 \pm 149$ dynes to $530 \pm 132$ dynes, respectively (mean $\pm 95 \%$ confidence interval). Mean PAP was decreased in response to 30,45 , or $60 \mu \mathrm{g}$ of inhaled treprostinil from $40.1 \pm 4.9 \mathrm{mmHg}$ to $33.3 \pm 4.4 \mathrm{mmHg}$, from $50.4 \pm 6.2 \mathrm{mmHg}$ to $38.1 \pm 8.4 \mathrm{mmHg}$ and from $39 \pm 4.8 \mathrm{mmHg}$ to $32.2 \pm 4.9 \mathrm{mmHg}$, respectively. These acute effects on hemodynamics were comparable with inhaled nitric oxide at $20 \mathrm{ppm}$. Interestingly, CTEPH patients responded as well as PAH patients. No worsening of ventilation/perfusion relationships, as assessed by the multiple inert gas elimination technique in five patients, were noted in response to inhaled treprostinil by MDI. Determination of the efficacy and safety of inhaled treprostinil using an MDI awaits a long-term randomized controlled trial.

\section{Use of inhaled treprostinil in clinical practice: where does it fit?}

Based on the results of a well-designed controlled trial, inhaled treprostinil is an efficacious treatment in patients who have moderately symptomatic pulmonary arterial hypertension on background oral therapy. There are compelling data to suggest that the presence of moderate functional limitations (Class III) and poor exercise capacity ( $<380 \mathrm{~m}$ in some retrospective studies) on initial therapy portends a poor prognosis. ${ }^{29,30}$ In addition, the concept of treating patients to goal (Class II, improved walk distance) has gained traction. ${ }^{31,32}$ Combination therapy may benefit many patients after re-evaluation of clinical effect of the first-line treatment (in general after three months of initiating therapy). Given that the benefits of oral PAH therapies on exercise capacity appear to plateau within three to six months, this timeframe seems reasonable to decide whether to add inhaled treprostinil to oral therapy. Given the efficacy of inhaled treprostinil, coupled with convenience and an acceptable side effect profile, it may be tempting to some physicians to start this medication earlier in the course of the disease or treatment as up-front combination therapy with an oral agent. However, this specific approach has not been tested systematically. Finally, it is compelling to consider the replacement of continuously parenteral prostacyclin analog therapy with inhaled treprostinil in combination with an oral agent (PDE-5 inhibitor or endothelin receptor antagonist). This approach should only be considered by those highly experienced in the care of PAH patients. While several patients have been transitioned safely from continuous intravenous or subcutaneous prostacyclin analogs to regimens containing inhaled treprostinil and an oral agent (unpublished data), this approach has not been systematically studied to date. It may be feasible only in carefully selected patients who are able to tolerate intermittent exposure to prostacyclin analogs.

\section{Conclusions}

Treprostinil is a highly active prostacyclin analog demonstrated to have short- and, in the case of parenteral delivery, long-term efficacy in PAH. The nature of the molecule, including potency, stability, half-life, and the ability to be aerosolized lend itself to delivery via an inhaled route using an ultrasonic nebulizer. Studies have confirmed the robust benefits and safety of inhaled treprostinil and it is now a valuable part of the treatment armamentarium. 
Based on the in vitro and in vivo pharmacological action of treprostinil, namely vasodilatation, prevention of smooth muscle cell proliferation, and its antithrombotic properties, investigating the role of inhaled treprostinil in other forms of non-WHO Group I pulmonary hypertension may be warranted.

\section{Acknowledgment}

The authors acknowledge and appreciate the assistance of Dr Tommy Brock from United Therapeutics, Inc for his assistance in the preparation of this manuscript.

\section{Disclosure}

Drs Channick, Voswinckel and Rubin have served as investigators and consultants for LungRx. Dr Rubin serves on the Scientific Advisory Board of United Therapeutics, the parent company for LungRx.

\section{References}

1. D'Alonzo GE, Barst RJ, Ayres SM, et al. Survival in patients with primary pulmonary hypertension. Results from a national prospective registry. Ann Intern Med. 1991;115:343-349.

2. Barst RJ, Rubin LJ, Long WA, et al. A comparison of continuous intravenous epoprostenol (prostacyclin) with conventional therapy for primary pulmonary hypertension. The Primary Pulmonary Hypertension Study Group. N Engl J Med. 1996;334:296-302.

3. Simonneau G, Barst RJ, Galie N, et al; Treprostinil Study Group. Continuous subcutaneous infusion of treprostinil, a prostacyclin ana$\log$, in patients with pulmonary arterial hypertension: a double-blind, randomized, placebo-controlled trial. Am J Respir Crit Care Med. 2002;165:800-804.

4. Olschewski H, Simonneau G, Galie N, et al; Aerosolized Iloprost Randomized Study Group. Inhaled iloprost for severe pulmonary hypertension. $N$ Engl J Med. 2002;347:322-329.

5. Channick RN, Simonneau G, Sitbon O, et al. Effects of the dual endothelin-receptor antagonist bosentan in patients with pulmonary hypertension: a randomized placebo-controlled study. Lancet. 2001;358:1119-1123.

6. Rubin LJ, Badesch DB, Barst RJ, et al. Bosentan therapy for pulmonary arterial hypertension. $N$ Engl J Med. 2002;346:896-903.

7. Galie N, Ghofrani HA, Torbicki A, et al; Sildenafil Use in Pulmonary Arterial Hypertension (SUPER) Study Group. Sildenafil citrate therapy for pulmonary arterial hypertension. $N$ Engl $J$ Med. 2005;353:2148-2157.

8. Galiè N, Olschewski H, Oudiz RJ, et al; Ambrisentan in Pulmonary Arterial Hypertension, Randomized, Double-Blind, Placebo-Controlled, Multicenter, Efficacy Studies (ARIES) Group. Ambrisentan for the treatment of pulmonary arterial hypertension: results of the ambrisentan in pulmonary arterial hypertension, randomized, double-blind, placebocontrolled, multicenter, efficacy (ARIES) study 1 and 2. Circulation. 2008;117:3010-3019.

9. Galiè N, Brundage BH, Ghofrani HA, et al; Pulmonary Arterial Hypertension and Response to Tadalafil (PHIRST) Study Group. Tadalafil therapy for pulmonary arterial hypertension. Circulation. 2009;119:2894-2903.

10. Barst RJ, Gibbs JS, Ghofrani HA, et al. Updated evidence-based treatment algorithm in pulmonary arterial hypertension. J Am Coll Cardiol. 2009; 54(Suppl):S78-S84.
11. McLaughlin VV, Archer SL, Badesch DB, et al. ACCF/AHA 2009 expert consensus document on pulmonary hypertension: a report of the American College of Cardiology Foundation Task Force on Expert Consensus Documents and the American Heart Association. J Am Coll Cardiol. 2009;53:1573-1619.

12. Galiè N, Hoeper MM, Humbert M, et al. Guidelines for the diagnosis and treatment of pulmonary hypertension: the Task Force for the Diagnosis and Treatment of Pulmonary Hypertension of the European Society of Cardiology (ESC) and the European Respiratory Society (ERS), endorsed by the International Society of Heart and Lung Transplantation (ISHLT). Eur Heart J. 2009;30:2493-2537.

13. McLaughlin VV, Benza RL, Rubin LJ, et al. Addition of inhaled treprostinil to oral therapy for pulmonary arterial hypertension: a randomized controlled clinical trial. $J$ Am Coll Cardiol. 2010;55: 1915-1922.

14. Sandifer B, Brigham K, Lawrence E, et al. Potent effects of aerosol compared with intravenous treprostinil on the pulmonary circulation. J Appl Physiol. 2005;99:2363-2368.

15. Laliberte K, Arneson C, Jeffs R, Hunt T, Wade M. Pharmacokinetics and steady-state bioequivalence of treprostinil sodium (Remodulin) administered by the intravenous and subcutaneous route to normal volunteers. J Cardiovasc Pharmacol. 2004;44:209-214.

16. Gotzkowsky SK, Dingemanse J, Lai A, Mottola D, Laliberte K. Lack of a pharmacokinetic interaction between oral treprostinil and bosentan in healthy adult volunteers. $J$ Clin Pharmacol. 2010;50:829-834.

17. Voswinckel R, Enke B, Reichenberger F, et al. Favorable effects of inhaled treprostinil in severe pulmonary hypertension: results from randomized controlled pilot studies. J Am Coll Cardiol. 2006;48: 1672-1681.

18. Channick RN, Olschewski H, Seeger W, et al. Safety and efficacy of inhaled treprostinil as add-on therapy to bosentan in pulmonary arterial hypertension. J Am Coll Cardiol. 2006;48:1433-1437.

19. Nelsen AC, Laliberte KJ, Zaccardelli DS, Gotzkowsky SK. Pharmacokinetics of inhaled treprostinil sodium in healthy volunteers. $\mathrm{Am} \mathrm{J}$ Respir Crit Care Med. 2010;181:A3348.

20. Barst RJ, Galie N, Naeije R, et al. Long-term outcome in pulmonary arterial hypertension patients treated with subcutaneous treprostinil. Eur Respir J. 2006;28:1195-1203.

21. Mathier MA, McDevitt S, Saggar R. Subcutaneous treprostinil in pulmonary arterial hypertension: Practical considerations. J Heart Lung Transplant. 2010;29:1210-1217.

22. Tapson VF, Gomberg-Maitland M, McLaughlin VV, et al. Safety and efficacy of IV treprostinil for pulmonary arterial hypertension: a prospective, multicenter, open-label, 12-week trial. Chest. 2006;129: 683-688.

23. Hiremath J, Thanikachalam S, Parikh K, et al; TRUST Study Group. Exercise improvement and plasma biomarker changes with intravenous treprostinil therapy for pulmonary arterial hypertension: a placebocontrolled trial. J Heart Lung Transplant. 2010;29:137-149.

24. Voswinckel R, Ghofrani H, Grimminger F, Seeger W. Inhaled treprostinil for treatment of chronic pulmonary hypertension. Ann Intern Med. 2006;144:149-150.

25. Voswinckel R, Reichenberger F, Enke B, et al. Acute effects of the combination of sildenafil and inhaled treprostinil on haemodynamics and gas exchange in pulmonary hypertension. Pulm Pharmacol Ther. 2008;21:824-832.

26. Benza R, Rubin LJ, McLaughlin VV, et al. TRIUMPH 1: Long-term safety and efficacy of inhaled treprostinil sodium in patients with PAH two year follow-up. Am J Respir Crit Care Med. 2009;179:A1041.

27. Bourge R, Tapson VF, Safdar Z, et al. Safely transitioning from inhaled iloprost to inhaled treprostinil sodium - results from a multicenter open-label study in patients with pulmonary arterial hypertension. $\mathrm{Am}$ J Respir Crit Care Med. 2010;181:A3342.

28. Voswinckel R, Reichenberger F, Gall H, et al. Metered dose inhaler delivery of treprostinil for the treatment of pulmonary hypertension. Pulm Pharmacol Ther. 2009;22:50-56. 
29. McLaughlin VV, Shillington A, Rich S. Survival in primary pulmonary hypertension: the impact of epoprostenol therapy. Circulation. 2002;106:1477-1482.

30. Sitbon O, Humbert M, Nunes H, et al. Long-term intravenous epoprostenol infusion in primary pulmonary hypertension: prognostic factors and survival. J Am Coll Cardiol. 2002;40:780-788.
31. Hoeper MM, Markevych I, Spiekerkoetter E, Welte T, Niedermeyer J. Goal-oriented treatment and combination therapy for pulmonary arterial hypertension. Eur Respir J. 2005;26:858-863.

32. Sitbon O, Galiè N. Treat-to-target strategies in pulmonary arterial hypertension: the importance of using multiple goals. Eur Respir Rev. 2010;19:272-278.

\section{Publish your work in this journal}

Drug Design, Development and Therapy is an international, peerreviewed open-access journal that spans the spectrum of drug design and development through to clinical applications. Clinical outcomes, patient safety, and programs for the development and effective, safe, and sustained use of medicines are a feature of the journal, which has also been accepted for indexing on PubMed Central. The manuscript management system is completely online and includes a very quick and fair peer-review system, which is all easy to use. Visit http://www.dovepress.com/testimonials.php to read real quotes from published authors.

Submit your manuscript here: http://www.dovepress.com/drug-design-development-and-therapy-journal 